\title{
Comparative Evaluation of Etomidate and Propofol Anaesthesia Following Atropine, Diazepam and Fentanyl Premedication in Geriatric Dogs
}

\author{
A.U. Hareesh ${ }^{1}$, P. Veena ${ }^{1 *}$, N. Dhanalakshmi ${ }^{1}$ and K. Veerabrahmaiah ${ }^{2}$ \\ ${ }^{1}$ Department of Veterinary Surgery and Radiology, ${ }^{2}$ Department of Veterinary Gynaecology \\ and obstetrics, College of Veterinary Science, Tirupati (A.P.), India \\ *Corresponding author
}

\section{A B S T R A C T}

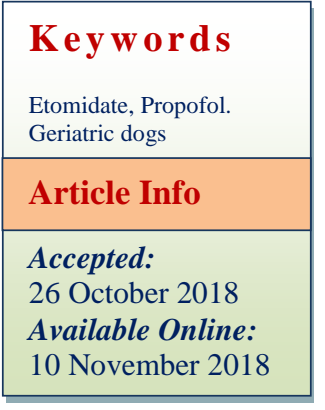

\section{Introduction}

Anaesthesia is an indispensable pre-requisite to most of the surgical interventions, both in humans and animals, so that the surgeon can perform surgical intervention with maximum precision and sagacity.

Procedural sedation and Analgesia (PSA) is a sedation technique involving the use of sedatives, dissociative agents and analgesics alone or in combination. Analgesics are used to treat pain and sedatives and/or dissociative agents are used to alleviate fear and anxiety. The goals of PSA are to relieve fear and anxiety, provide analgesia, sedation and amnesia as needed for an unpleasant procedure in order to minimize adverse effects of agents, maintain cardiorespiratory functions and control motor behavior. The ideal agents for PSA satisfy all of these goals have a rapid onset and short duration, have the same effect irrespective of the route of administration and are reversible, safe at all ages and simple to administer.

Because no such ideal single agent exists, PSA agents must be chosen in combination or alone single drug in order to provide as many of the desired goals as possible.

There is paucity of literature available on 
Etomidate and Propofol anaesthesia following Atropine, Diazepam and Fentanyl premedication in Geriatric dogs. Therefore in the present study, this combination of drugs was evaluated together for their safety and efficacy to induce general anaesthesia in geriatric dogs.

\section{Materials and Methods}

Dogs with various surgical problems belong to different breeds, aged between 7 to 14 years with a body weight ranged between 14 to 43 kgs were utilized for the study. All these dogs were randomly selected and routine clinical and haematological examinations were carried out and those were found to be fit for surgery were utilized for study. All the dogs were withheld food and water for twelve hours prior to administration of anaesthetic drugs.

All the dogs under study were premedicated with atropine sulphate at the dose rate of $0.04 \mathrm{mg} / \mathrm{kg}$ body weight subcutaneously. Ten minutes after premedication, the dogs were sedated with diazepam at the dose rate of 0.5 $\mathrm{mg} / \mathrm{kg}$ body weight and fentanyl @ $0.002 \mathrm{mg} /$ $\mathrm{kg}$ body weight intravenously. After premedication, the animals were divided in to two groups of six animals each as follows.

Group I: Dogs were subjected to Etomidate anaesthesia $0.3 \mathrm{mg} / \mathrm{kg}$ b.wt intravenously.

Group II: Dogs were given propofol anaesthesia @ $6 \mathrm{mg} / \mathrm{kg}$ body weight intravenously.

The character of anaesthesia during induction, surgical plane of anaesthesia and recovery was assessed. Physiological parameters like rectal temperature, respiratory rate, pulse rate, pulse oximetry values $\left(\mathrm{SpO}_{2}\right)$ were recorded before and at 5, 10, 15, 30, 60 minutes and $2 \mathrm{hrs}$ time intervals of anaesthesia.

Results and Discussion
In the present study, mean value of induction of anaesthesia was $21 \pm 0.516$ seconds in group I and induction was smooth, rapid and excitement free with etomidate anaesthesia compared with propofol. Premedication with atropine, diazepam and fentanyl reduced the induction dose of etomidate and propofol significantly and prolonged the period of anaesthesia (Perk et al., 2002 and Tomas et al., 2014). However, good surgical anaesthesia with adequate muscle relaxation was observed in animals of both groups in this study.

The recovery from anaesthesia was rapid and smooth without struggling in both groups. There was no significant difference in recovery time in both groups. However, smooth but slightly prolonged recovery was a consistent observation in propofol group in this study, which might be attributed that high dose of propofol reduced the clearance of fentanyl which is because of inhibition of microsomal enzymes that are responsible for metabolism of fentanyl (Andreoni and Hughes 2009).

In the present study, a significant decrease in rectal temperature was recorded in both groups during anaesthesia and surgery (Table 1). Hypothermia was probably produced by the sedative and anaesthetics used, which decreased rectal temperature by depression of thermoregulatory centre, reduced BMR and muscle activity, depression of peripheral circulation and vasodilatation. Similar findings were reported by Hughes and Nolan (1999) in dogs with propofol and fentanyl combination. Perk et al., (2002) also recorded decrease in rectal temperature following etomidate - alfentanil anaesthesia in dogs.

A non-significant decrease in respiratory rate was observed in etomidate group after premedication and induction of anaesthesia, which might be attributed to the use of opioid 
in this study. On the contrary, Goroszeniuk et al., (1986) observed stable respiratory rate with etomidate - fentanyl anaesthesia in humans.

A significant decrease in respiratory rate was observed in group II dogs following premedication and induction of anaesthesia. In the present study, severe respiratory depression was a consistent finding up to $2 \mathrm{hrs}$ interval in group II dogs (Table 1). These findings were in accordance with the earlier studies in which a greater respiratory depression was observed when propofol was used alone or in combination with opioids in dogs as also reported by Hughes and Nolan (1999). Propofol caused a decrease in mean respiratory rate by depressing central inspiratory drive and the ventilatory response to arterial $\mathrm{CO}_{2}$ tension. In the present study, transient apnoea was observed immediately after propofol induction in group II animals.

In the present study, a significant decrease in pulse rate was observed in etomidate group whereas, a significant decrease in pulse rate was noticed in dogs subjected to propofol anaesthesia (Table 1). Sams et al., (2008) also recorded significant decrease in pulse rate following etomidate anaesthesia in dogs.

The administration of propofol is generally associated with decrease in pulse rate. This depression is believed to be a dose-dependent lowering of sympathetic tone, in addition to direct negative inotropic and venodilator effects as also reported by Sams et al., (2008). Pulse oximetry was used to estimate $\mathrm{SpO}_{2}$ in the present study. It was relatively accurate, non-invasive, immediate, continuous and portable method to monitor the percentage of oxygen saturation of arterial haemoglobin. Decrease in $\mathrm{SpO}_{2}$ was seen in animals of both groups throughout the period of observation. This decrease was significant after 10 minutes of drug administration in both groups, (Table
1) which might be due to a certain degree of respiratory depression by the anaesthetics. In the contrary, Perk et al., (2002) in dogs observed no changes in $\mathrm{SpO}_{2}$ during etomidate anaesthesia.

The pre-anaesthetic mean values of heart rate in group I and II was $113 \pm 7.14$ and $117.00 \pm 3.95$ beats $/ \mathrm{min}$ respectively. There was a non-significant decrease in heart rate in group I animals throughout the period of study. In group II dogs, a significant decrease in heart rate $(\mathrm{P} \leq 0.05)$ was observed. The variations in heart rate between the groups were signficant $(\mathrm{P} \leq 0.05)$ throughout the study. However, the fluctuations were within the normal physiological range. There was an increase in amplitude of QRS complex indicating delayed ventricular depolarization in animals of both groups after premedication and was seen throughout the observation period as reported by Pereira et al., (2001). However, Jang et al., (2015) reported severe bradycardia and a systole following fentanyl isoflurane anaesthesia in dogs. Whereas, Chang et al., (2008) recorded prolonged QTc during propofol induction in humans.

In our study, haemoglobin and PCV decreased non significantly in group I dogs during the period of study (Table 1). Sams et al., (2008) observed significant decrease in PCV during etomidate anaesthesia in dogs whereas, Perk et al., (2002) recorded no significant changes in haematological parameters following etomidate - alfentanil anaesthesia in dogs.

A significant decrease in haemoglobin and PCV was observed in dogs subjected to propofol anaesthesia during the period of study (Table 2). Pooling of circulatory blood cells in the spleen or other reservoirs secondary to decreased sympathetic activity explained the decrease in haemoglobin and PCV. 
Table.1 Variations in mean \pm SE values of different physiological parameters before, during and after anaesthesia in Geriatric dogs

\begin{tabular}{|c|c|c|c|c|c|c|c|c|c|}
\hline \multirow[t]{2}{*}{ Parameters } & \multirow{2}{*}{ Groups } & \multicolumn{6}{|c|}{ Minutes } & \multirow[b]{2}{*}{$2 \mathrm{hrs}$} & \multirow[b]{2}{*}{$\begin{array}{l}\text { Overall } \\
\text { mean }\end{array}$} \\
\hline & & $\mathbf{0}$ & 5 & 10 & 15 & 30 & 60 & & \\
\hline \multirow[t]{2}{*}{ Temperature $\left({ }^{\circ} \mathbf{F}\right)$} & Group I & $102.55 \pm 0.45^{\mathrm{a}}$ & $102.26 \pm 0.43^{\mathrm{ab}}$ & $101.96 \pm 0.43^{\mathrm{abc}}$ & $101.63 \pm 0.42^{\mathrm{abc}}$ & $101.36 \pm 0.43^{b c}$ & $100.95 \pm 0.30^{c}$ & $100.40 \pm 0.23^{\mathrm{cd}}$ & $101.59 \pm 0.17^{\mathrm{A}}$ \\
\hline & Group II & $101.88 \pm 0.10^{\mathrm{a}}$ & $101.33 \pm 0.13^{b}$ & $100.90 \pm 0.13^{c}$ & $100.53 \pm 0.12^{\mathrm{cd}}$ & $100.25 \pm 0.12^{\text {cde }}$ & $99.98 \pm 0.13^{\mathrm{ce}}$ & $99.73 \pm 0.12^{\text {ef }}$ & $100.65 \pm 0.11^{\mathrm{B}}$ \\
\hline \multirow{2}{*}{$\begin{array}{l}\text { Respiratory rate } \\
\text { (breaths/minute) }\end{array}$} & Group I & $53.50 \pm 5.91^{\mathrm{a}}$ & $47.33 \pm 4.45^{\mathrm{a}}$ & $50.00 \pm 5.50^{\mathrm{a}}$ & $48.50 \pm 5.82^{\mathrm{a}}$ & $47.50 \pm 5.61^{\mathrm{a}}$ & $43.50 \pm 5.26^{\mathrm{a}}$ & $40.16 \pm 4.21^{\mathrm{a}}$ & $47.21 \pm 1.95^{\mathrm{A}}$ \\
\hline & Group II & $52.33 \pm 3.19^{\mathrm{a}}$ & $47.16 \pm 3.45^{\mathrm{ab}}$ & $42.00 \pm 3.64^{b}$ & $39.00 \pm 3.85^{b}$ & $32.00 \pm 1.71^{\mathrm{bc}}$ & $28.33 \pm 1.58^{\mathrm{cd}}$ & $24.50 \pm 1.38^{\mathrm{cd}}$ & $37.90 \pm 1.77^{\mathrm{B}}$ \\
\hline \multirow{2}{*}{$\begin{array}{l}\text { Pulse rate } \\
\text { (beats/minute) }\end{array}$} & Group I & $135.83 \pm 7.35^{\mathrm{a}}$ & $130.50 \pm 7.28^{\mathrm{ab}}$ & $124.83 \pm 7.08^{\mathrm{abc}}$ & $118.66 \pm 5.92^{\mathrm{abc}}$ & $115.66 \pm 6.74^{b}$ & $111.00 \pm 6.27^{b c}$ & $106.50 \pm 5.13^{b c}$ & $120.42 \pm 2.75^{\mathrm{A}}$ \\
\hline & Group II & $143.66 \pm 8.41^{\mathrm{a}}$ & $134.33 \pm 7.27^{\mathrm{ab}}$ & $127.50 \pm 7.00^{\mathrm{abc}}$ & $119.83 \pm 6.52^{\mathrm{abcd}}$ & $114.83 \pm 5.88^{\mathrm{bcc}}$ & $108.66 \pm 4.88^{\mathrm{bcc}}$ & $103.50 \pm 4.28^{\mathrm{bcc}}$ & $121.76 \pm 3.05^{\mathrm{A}}$ \\
\hline \multirow{2}{*}{$\begin{array}{l}\text { Heart rate } \\
\text { (beats/minutes) }\end{array}$} & Group I & $113.33 \pm 7.14^{\mathrm{a}}$ & $111.00 \pm 6.90^{\mathrm{a}}$ & $108.33 \pm 6.73^{a}$ & $106.83 \pm 6.98^{a}$ & $104.33 \pm 6.80^{a}$ & $106.00 \pm 7.15^{\mathrm{a}}$ & $107.00 \pm 7.29^{\mathrm{a}}$ & $108.11 \pm 2.48^{\mathrm{A}}$ \\
\hline & Group II & $117.00 \pm 3.95^{\mathrm{a}}$ & $106.16 \pm 3.88^{b}$ & $100.00 \pm 8.12^{b c}$ & $96.00 \pm 4.76^{\mathrm{cd}}$ & $87.83 \pm 2.56^{\mathrm{de}}$ & $79.33 \pm 31.42^{\mathrm{ef}}$ & $71.33 \pm 0.98^{f}$ & $93.95 \pm 2.54^{\mathrm{B}}$ \\
\hline \multirow{2}{*}{$\begin{array}{l}\mathrm{Spo}_{2} \\
\text { (percentage) }\end{array}$} & Group I & $97.79 \pm 0.27^{\mathrm{a}}$ & $97.32 \pm 0.28^{\mathrm{ab}}$ & $96.86 \pm 0.25^{\mathrm{abc}}$ & $96.58 \pm 0.22^{b c}$ & $96.27 \pm 0.19^{c}$ & $96.05 \pm 0.19^{\text {cd }}$ & $95.82 \pm 0.19^{\text {cde }}$ & $96.67 \pm 0.13^{A}$ \\
\hline & Group II & $98.69 \pm 0.06^{\mathrm{a}}$ & $97.46 \pm 0.13^{b}$ & $96.31 \pm 0.11^{\mathrm{c}}$ & $95.79 \pm 0.08^{\mathrm{d}}$ & $95.35 \pm 0.10^{\mathrm{e}}$ & $95.39 \pm 0.08^{\mathrm{ef}}$ & $95.22 \pm 0.07^{\mathrm{ef}}$ & $96.32 \pm 0.19^{\mathrm{A}}$ \\
\hline
\end{tabular}

Means bearing different superscripts $(\mathrm{a}, \mathrm{b}, \mathrm{c}$. .) within a row differ significantly $(\mathrm{P} \leq 0.05)$

Means bearing different superscripts $(\mathrm{A}, \mathrm{B})$ within a column differ significantly $(\mathrm{P} \leq 0.05)$

Group I: Etomidate

Group II: Propofol 
Table.2 Variations in mean \pm SE values of different haematological parameters before, during and after anaesthesia in geriatric dogs

\begin{tabular}{|l|l|l|l|l|l|l|}
\hline Parameters & Groups & Minutes & & \\
\cline { 3 - 7 } & & $\mathbf{0}$ & $\mathbf{3 0}$ & $\mathbf{6 0}$ & 2 Hrs & Overall Mean \\
\hline $\begin{array}{l}\text { Haemoglobin } \\
\text { (grams / percentage) }\end{array}$ & Group I & $10.81 \pm 1.10^{\mathrm{a}}$ & $10.00 \pm 1.01^{\mathrm{a}}$ & $9.26 \pm 0.83^{\mathrm{a}}$ & $8.90 \pm 0.75^{\mathrm{a}}$ & $9.74 \pm 0.46^{\mathrm{A}}$ \\
\hline $\begin{array}{l}\text { Packedcell volume } \\
\text { (percentage) }\end{array}$ & Group I & $10.70 \pm 0.47^{\mathrm{a}}$ & $8.96 \pm 0.31^{\mathrm{b}}$ & $8.45 \pm 0.21^{\mathrm{b}}$ & $8.05 \pm 0.16^{\mathrm{b}}$ & $9.04 \pm 0.25^{\mathrm{A}}$ \\
\cline { 2 - 8 } & Group II & $32.45 \pm 3.30^{\mathrm{a}}$ & $30.00 \pm 3.03^{\mathrm{a}}$ & $27.80 \pm 2.49^{\mathrm{a}}$ & $26.53 \pm 2.32^{\mathrm{a}}$ & $29.19 \pm 1.39^{\mathrm{A}}$ \\
\hline
\end{tabular}

Means bearing different superscripts within a row $(a, b \ldots)$ vary significantly $(\mathrm{P} \leq 0.05)$

Group I: Etomidate

Group II: Propofol

Table.3 Variations in mean \pm SE values of different biochemical parameters before, during and after anaesthesia in geriatric dogs

\begin{tabular}{|c|c|c|c|c|c|c|}
\hline \multirow[t]{2}{*}{ Parameters } & \multirow[t]{2}{*}{ Groups } & \multicolumn{5}{|c|}{ Minutes } \\
\hline & & 0 & 30 & 60 & $2 \mathrm{Hrs}$ & Overall Mean \\
\hline \multirow{2}{*}{$\begin{array}{l}\text { Aspartate amino } \\
\text { transferase (I.U/ml) }\end{array}$} & Group I & $37.40 \pm 2.54^{\mathrm{a}}$ & $36.71 \pm 2.69^{\mathrm{a}}$ & $42.69 \pm 2.97^{\mathrm{ab}}$ & $47.24 \pm 3.61^{\mathrm{ab}}$ & $41.01 \pm 1.65^{\mathrm{A}}$ \\
\hline & Group II & $51.79 \pm 7.95^{\mathrm{a}}$ & $71.87 \pm 7.65^{\mathrm{ab}}$ & $82.74 \pm 7.84^{b}$ & $93.36 \pm 7.41^{b}$ & $74.94 \pm 4.81^{\mathrm{B}}$ \\
\hline \multirow{2}{*}{$\begin{array}{l}\text { Alanine amino } \\
\text { transferase (I.U/ml) }\end{array}$} & Group I & $25.43 \pm 3.90^{\mathrm{a}}$ & $26.43 \pm 4.39^{a}$ & $33.86 \pm 5.74^{\mathrm{a}}$ & $37.71 \pm 5.84^{\mathrm{a}}$ & $30.82 \pm 2.58^{\mathrm{A}}$ \\
\hline & Group II & $28.70 \pm 5.58^{a}$ & $37.86 \pm 6.95^{\mathrm{a}}$ & $49.05 \pm 7.64^{\mathrm{ab}}$ & $59.23 \pm 8.36^{b c}$ & $43.71 \pm 4.12^{\mathrm{B}}$ \\
\hline \multirow{2}{*}{$\begin{array}{c}\text { Alkaline phosphatase } \\
\text { (I.U/ml) }\end{array}$} & Group I & $71.94 \pm 11.01^{\mathrm{a}}$ & $90.17 \pm 13.70^{\mathrm{a}}$ & $102.98 \pm 12.62^{\mathrm{a}}$ & $106.70 \pm 10.39^{\mathrm{a}}$ & $92.95 \pm 6.27^{\mathrm{A}}$ \\
\hline & Group II & $72.38 \pm 12.31^{a}$ & $94.33 \pm 15.02^{\mathrm{a}}$ & $112.71 \pm 14.42^{\mathrm{ab}}$ & $127.56 \pm 12.17^{\mathrm{ab}}$ & $101.74 \pm 7.64^{\mathrm{A}}$ \\
\hline
\end{tabular}

Means bearing different superscripts within a row (a, b...) vary significantly $(\mathrm{P} \leq 0.05)$

Group I: Etomidate

Group II: Propofol 
The decrease in haemoglobin and PCV during the period of anaesthesia or sedation might be due to shifting of fluid from extravascular compartment to intravascular compartment in order to maintain normal cardiac output in animals (Kushwaha et al., 2012). The decrease in haemoglobin and PCV was reported after administration of propofol in dogs (Sear et al., 1985, Gill et al., 1996 and Kushwaha et al., 2012). This is in contrary with the findings of Bayan et al., (2002), who observed increase in haemoglobin values during propofol anaesthesia in dogs. Muir and Gadawski (1998), Lim-Jaehyun et al., (2000) and Saritas et al., (2014) recorded no significant changes in haemoglobin during anaesthesia in dogs.

A non-significant increase in AST, ALT and AKP was noticed in group I dogs throughout the period of observation but this increase was within normal physiological limit which indicated the possibility of pathological changes in the liver could therefore, be ruled out (Table 3). However, Perk et al., (2002) recorded no significant change in AST, ALT during etomidate - alfentanil anaesthesia in dogs. A significant increase in AST, ALT and AKP values were recorded in dogs subjected to propofol anaesthesia, throughout the study. It corroborates with the findings of Bayan et al., (2002) who recorded significant increase in AST, ALT values during propofol anaesthesia in dogs. However, Muir and Gadawski (1998) and Lim-Jaehyun et al., (2000) during propofol anaesthesia in dogs, Kim-Jiwan et al., (1999) with propofolxylazine anaesthesia in dogs reported no significant changes in AST and ALT during anaesthesia. In the contrary, decreases in AST and ALT values were reported by Kwon Youngsam et al., (1999) during propofol anaesthesia in dogs.

Age itself is not a contraindication for anaesthesia; however, age-related diseases make anaesthesia more challenging. Though pre-operative assessment, careful choice of anaesthetic and analgesic techniques, vigilant monitoring and attentive supportive care will improve the probability of a successful outcome for the elderly patient.

It is concluded that both anaesthetic drug combinations can be used in geriatric dogs for major surgical procedures. However, etomidate is better for its haemodynamic stability over propofol. Hence, combination of etomidate following atropine, diazepam and fentanyl premedication can be relied on for both induction and maintenance of anaesthesia and for brief surgical procedures in geriatric dogs.

\section{References}

Bayan H, Sharma K K and Chakravarthy $\mathrm{P}$ 2002 Biochemical and haematological changes of propofol anaesthesia in canines. Indian Journal of Veterinary Surgery 23 (2): 95-96.

Gill J R, Rodriguez J F, Ezquerra L J, Vives M A, Jimenez J and Uson J M 1996 Development of anaesthesia and changes in blood parameters in dogs medicated with propofol. Medicina Veterinaria 13: 242-246.

Goroszeniuk T, Albin M and Jones R M 1986 Generalized grand mal seizure after recovery from uncomplicated fentanyletomidate anaesthesia. International Anaesthesia Research Society 65:97981.

Hughes L J M and Nolan M A 1999 Total intravenous in Grey-hounds: pharmacokinetics of propofol and fentanyl a preliminary study. Veterinary Surgery 28:513-524.

Kim-Jiwan, Jang-In H O, Kim J W and Jang I $\mathrm{H}$ 1999. The effects of xylazine premedication on propofol anaesthesia 
in the dog. Korean Journal of Veterinary Clinical Medicine 16: 86-94.

Kushwaha J P, Malik V and Singh B 2012 Evaluation of midazolam and propofol in different combinations for clinical anaesthesia in dogs. Indian Journal of Veterinary Surgery 33(2): 77-81.

Kwon-Youngsam, Jang- Kwang H O, KimJung Evn, Chae- Hyung G Y V, LimJaehyun Lee Kevn Woo, Jang-IN H O, Kwon Y S, Jang K H, Kim J E, Chae H $\mathrm{G}$, Lim $\mathrm{J} \mathrm{H}$, Lee $\mathrm{K} \mathrm{W}$ and Jang $\mathrm{I} \mathrm{H}$ 1999 Effects of continuous administration of propofol in dogs. Korean Journal of Veterinary Clinical Medicine 16: 363-368.

Lim-Jaehyun, Jang-kmangho, Jang-In Ho, Lim J H and Jang I H 2000 Comparative effects of propofol infusion rate during maintenance of anaesthesia in dogs. Korean Journal of Veterinary Clinical Medicine 17(1):109-120.

Muir W W and Gadawski J E 1998 Respiratory depression and aponea induced by propofol in dogs. American Journal of Veterinary Research 59(2):157-161.
Perk C, Guzel O and Gulanber E G 2002 Etomidate/Alfentanil anaesthesia in dogs and its effects on pulse oximeter, electrocardiography and haematological parameters. Turkish Journal of Veterinary and Animal Science 26: 1021-1024.

Sams L, Braun C, Allman D and Hofmeister E A 2008 Comparison of the effects of propofol and etomidate on the induction of anaesthesia and on cardiopulmonary parameters in dogs. Veterinary Anaesthesia and Analgesia 35: 488-494.

Saritas Z K, Saritas T B, Pamuk K, Korkmaz M, Demirkan I, Yaprakci M V and Sivaci R G 2014 Comparison of the effects of lidocaine and fentanyl in epidural anaesthesia in dogs. Bratislava Medical Journal 115(8): 508-513.

Schalm O W, Jain N C and Correl E J 1975 Veterinary Haematology. Edn, $3^{\text {rd }}$, Lea and Febiger. Philadelphia, pp 45-61.

Sear J W, Uppington J and Kay N H 1985 Haematological and biochemical changes during anaesthesia with propofol. Post Graduate Medical Journal 61(3): 165-168.

\section{How to cite this article:}

Hareesh, A.U., P. Veena, N. Dhanalakshmi and Veerabrahmaiah, K. 2018. Comparative Evaluation of Etomidate and Propofol Anaesthesia Following Atropine, Diazepam and Fentanyl Premedication in Geriatric Dogs. Int.J.Curr.Microbiol.App.Sci. 7(11): 3144-3150. doi: https://doi.org/10.20546/ijcmas.2018.711.361 